\title{
Heat Transfer Enhancement of Solar Flat Plate Collector by Using V Corrugated Fins and Various Parameters
}

\author{
Manoj S. Chaudhari ${ }^{*}$, Dattatraya. B. Nalawade ${ }^{2}$, Mahesh Jagadale ${ }^{3}$ \\ 1,3Department of Mechanical Engineering, SPP University, GSMCOE Balewadi, Pune-01, India \\ ${ }^{2}$ Department of Mechanical Engineering, SPP University, VIIT, Pune-01, India
}

Accepted 15 June 2016, Available online 20 June 2016, Special Issue-5 (June 2016)

\begin{abstract}
Solar flat plate collector can be defined as typical metal box covered with a coated glass (known as glazing) on the top and dark colored absorber plate at the bottom. It has insulation on sides and bottom in order to minimize the heat loss. In this project work, initially an experimental set up is made for studying the flow through domestic solar flat plate collector and record experimental observations. After completion of experiment a 3D mathematical model with single and double glazed covers of Solar Flat plate collector (SFPC) is prepared and model is analyzed for CFD flow and heat transfer. Moreover, in this project use of vortex generators (V corrugation over absorber plate) and heat enhancement setups such as double glazing, optimum air gap, use of different gases(air, carbon dioxide and argon) are considered so as to increase the heat transfer rate between the interacting fluids. The basic geometrical dimensions for the 3D mathematical model is based on domestically available SFPC on which experiment was performed and CAD model is prepared using Ansys Design Modeler. The prepared model is simulated in ANSYS Fluent 14.5 considering radiation, natural convection and conduction all modes of heat transfer in boundary conditions. A parametric study is done so as to understand the effect of air gap thickness and use of different gases on the heat transfer rate. A comparative study is carried on between models having $V$ corrugation and model having double glazing and another similar model but without fins and glazing, it was concluded that Heat transfer Enhancement occurs for models with double glazing and also with the use of $v$ corrugation over absorber plates.
\end{abstract}

Keywords: Glazing, Temperature, Fin, ANSYS Design Modular, ANSYS Fluent, Heat Transfer Enhancement

\section{Introduction}

With increasing living standards, growing world population and rapid developments in technology, raises the need for energy every day, however, meeting the demand is harder due to the limited energy reservoirs existed around the world. The environmental pollution resulting from the usage of conventional energy sources is another serious problem. Due to these difficulties related to the energy issue, the world is seeking for alternative energy sources If we look back to the 19th century, people used stoves to heat water by burning pieces of coal or wood . Duffie J. and Beckmann W suggested a remedy to avoid these problems, a much safer and easier way to heat water was invented. This was achieved by placing a black painted metal tank full of water outside to absorb solar energy. Klein and Duffie studied effects of thermal capacitance while modelling SFPC .They found that capacitance effect is significant due to variable whether conditions. They investigated three SFPC models - first model of zero capacitance, the

${ }^{*}$ Corresponding author: Manoj S. Chaudhari second model accounts for effects of capacitance assuming collector as unit and third model dividing the collector in nodes and isothermal segments. Wang and WU proposed discrete numerical model for flow distribution and in solar collector. They considered no uniform flow, conduction and effects of buoyancy and found good agreement with experimental results. Oliva et al. introduced another numerical method to determine solar collector thermal behavior. The distributed character model considers multidimensional and transient properties of heat transfer that characterize the solar collector, while of heat transfer flux by free convection at the air gap zone has been calculated using empirical expressions and the solar irradiance was integrated to be constant per hour. Anderson scrutinized different coloured solar collector performances. Based on the product of transmittance absorptance of collectors of different colours, theoretical performances of the used collectors were determined using the Hottel-WhillierBliss 1-D steady-state model presented by Duffie and Beckmann.

Gertzos and Caouris enquired into a different heat transfer enhancement approach which used a pump for 
circulating the storage water in the indirect heating flat plate collector. This resulted in an increase in the outlet service water temperature. For flat-plate solar collector, Cadaflach has presented a detailed numerical model. He noticed that the transfer of heat through the collector is essentially one dimensional. 2-D and 3-D effects almost always occur due to the influence due the edges and the non-uniform effects. A polymer solar collector developed by Martinopoulos et al., where the solar energy is directly absorbed by the black-colored working fluid. The model was examined both experimentally and with computational fluid dynamics (CFD). Kim and Kumarshowed the investigations in order to enhance the Nusselt number and pressure drop by the use of rib baffles of different shapes, sizes, and orientations to produce artificial roughness in oreder to create more friction. Kiran kumar and Ranga Babu investigated numerical and experimental analysis of SFPC in order to increase its thermal efficiency. The study made use of nano fluids like $\mathrm{Al}_{2} \mathrm{O}_{3}$ and $\mathrm{Cu}_{2} \mathrm{O}$ with water and predicted heat loss coefficients. From the above literature survey, it has been concluded that so much investigation has been done analytically and experimentally for enhancing the thermal performance of solar flat collector and these results are interpreted and validated against the CFD simulation.

However, many of these studies are considered constant heat flux condition and/or 1D/2D model. Hence, to understand the heat transfer phenomenon thoroughly, solar flat plate collector is modeled three dimensionally and actual solar radiation (which depends on geographical location, day and time) falling on the collector is taken into account. The aim of this thesis is to carry out parametric study on various parameters on a proposed design of a simple flat-plate glazed collectors suggesting possible design modifications which could prove healthy in future for increasing the performance and overall efficiency.

\section{Problem statement}

A 3D numerical model for flat-plate liquid solar collectors has been designed in ANSYS 14.5 design module. This model is used for enhancing heat transfer the collector, for which the different heat transfer mechanisms involved are simultaneously taken into account and used to reduce the overall heat loss: solar radiation absorption, transmission and reflection natural convection in the air cavity heat conduction across the tube-absorber welded junction mixed convection flow in the risers and heat losses by convection and radiation to the ambient. To ensure the reliability of the model, the heat transfer results inside the risers and in the air cavity were contrasted with experimental results.

\section{Objective}

Objectives of this thesis are as follows-1)Experimental set up and recording observations from domestically used Solar Flat plate collector. 2) A 3D geometric model of flat-plate solar liquid collectors has been developed in ANSYS Design Modular and has been solved in ANSYS 14.5 (Fluent). 3). To validate the simulated results with experimental values. 4). To observe the effects of variation of air gap thickness, Use of different gases between absorber plate and glass cover like air, $\mathrm{CO} 2$, argon gas, use of $\mathrm{V}$ corrugated absorber plate instead of flat plate and comparison of single and double glazing surface.

\section{Experimentation details and Specifications}

In the part of experimentation, various types of steps or parts are included as:

The specifications and detail of equipment's are mentioned below:

\section{Material and Specifications}

The specification is mentioned below:

Table 1: Solar Flat Plate Collector Specification

\begin{tabular}{|c|c|}
\hline $\begin{array}{l}\text { Solar flat plate } \\
\text { collector } \\
\text { components }\end{array}$ & $\begin{array}{l}\text { Solar flat plate collector cover plate made } \\
\text { of toughened glass. Sheet for absorber } \\
\text { made of copper. Absorber made of copper } \\
\text { sheet and copper tube }\end{array}$ \\
\hline a)Glass cover & $\begin{array}{c}\text { Cover plate: cover plate is toughened glass } \\
\text { and thickness of } 5.0 \mathrm{~mm}\end{array}$ \\
\hline b)Absorber plate & $\begin{array}{l}\text { Sheet for absorber is made from copper } \\
\text {,thickness }-1.2 \mathrm{~mm}\end{array}$ \\
\hline c) Air gap & $\begin{array}{l}\text { The air gap between the glazing and the } \\
\text { absorber is } 8 \mathrm{~mm}\end{array}$ \\
\hline $\begin{array}{l}\text { d)Inner tank or } \\
\text { cold tank }\end{array}$ & $\begin{array}{l}\text { Material- Stainless steel, } 2.4 \mathrm{~m} \text { from } \\
\text { terrace level }\end{array}$ \\
\hline $\begin{array}{l}\text { e) Gasket for } \\
\text { flanges }\end{array}$ & $\begin{array}{l}3 \mathrm{~mm} \text { thick gasket of rubber is used for } \\
\text { ceiling between flanges }\end{array}$ \\
\hline $\begin{array}{l}\text { f)Collector } \\
\text { Support frame }\end{array}$ & $\begin{array}{l}\text { Collector can withstand wind velocity of } \\
\qquad 100 \mathrm{~km} / \mathrm{hr}\end{array}$ \\
\hline $\begin{array}{l}\text { g)Storage Tank } \\
\text { or Hot water tank }\end{array}$ & Made of Stainless steel \\
\hline h) Insulation & Material- Rockwool \\
\hline
\end{tabular}

\section{A. Experimental Setup}

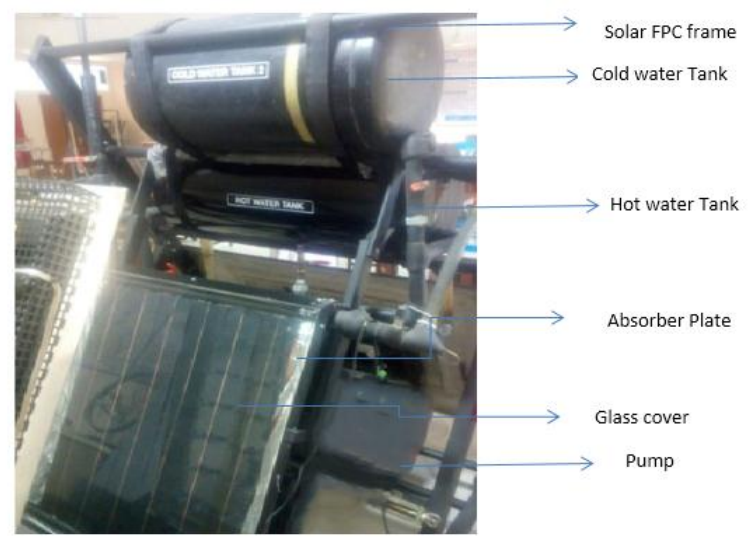

Fig.1 Set up of SFPC with six series pipe

The above figure shows setup of SFPC with cold water tank and hot water tank and six series pipe. The flow in 
SFPC is through natural convection that is through siphon action water in pipe flows from cold water tank to hot water tank, thus no requirement of pump. In this project our main aim is to increase the heat transfer to pipes for increasing water temperature at outlets.

The experimental set up of Solar FPC having two water tanks- Inlet and outlet tank, Solar FPC, Flow meter, pump and digital thermometer for measuring inlet and outlet water temperature. Our main objective is to increase outlet temperature so digital thermometers are placed for the purpose and flow meter is set up to measure mass flow rate of fluid entering solar FPC.

Table 2: Construction details of Solar FPC with their material properties based on observation

\begin{tabular}{|c|c|c|c|c|c|}
\hline 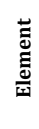 & 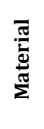 & 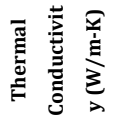 & 窵 & 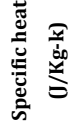 & 总 \\
\hline$\stackrel{\nexists}{\Xi}$ & 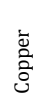 & 387.6 & 8978 & 381 & $\begin{array}{c}\text { I.D. }=11.58 \mathrm{~mm} \\
\text { O.D. }=12.7 \mathrm{~mm} \mathrm{\&} \\
\text { Length }=800 \mathrm{~mm}\end{array}$ \\
\hline 岕 & $\begin{array}{l}\mathscr{n} \\
\stackrel{\tilde{J}}{\mathrm{v}}\end{array}$ & 1.14 & 2230 & 750 & $\begin{array}{l}\text { Length }=805 \mathrm{~mm}, \\
\text { width }=800 \mathrm{~mm} \& \\
\text { thickness }=5 \mathrm{~mm}\end{array}$ \\
\hline 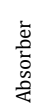 & 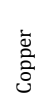 & 387.6 & 8978 & 381 & $\begin{array}{l}\text { Length }=805 \mathrm{~mm}, \\
\text { Width }=800 \mathrm{~mm} \& \\
\text { Thickness }=1.2 \mathrm{~mm}\end{array}$ \\
\hline 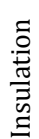 & 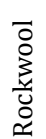 & 0.04 & 48 & 840 & $\begin{array}{c}\text { Bottom side }=50 \\
\mathrm{~mm} \\
\text { Edge side }=25 \mathrm{~mm}\end{array}$ \\
\hline
\end{tabular}

\section{Experimental Observations}

\begin{tabular}{|c|c|c|c|c|c|}
\hline$\sum_{i}^{\circ}$ & $\underset{\Xi}{\Xi}$ & 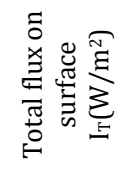 & 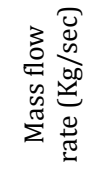 & 莺 & 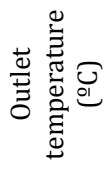 \\
\hline 1 & $\begin{array}{c}10 \\
\text { AM }\end{array}$ & 782.461 & 0.0063 & 27 & 30.2 \\
\hline 2 & $\begin{array}{c}11 \\
\mathrm{AM}\end{array}$ & 814.3508 & 0.0063 & 28.3 & 32.7 \\
\hline 3 & $\begin{array}{c}12 \\
\text { PM }\end{array}$ & 826.4204 & 0.0063 & 30.1 & 35.2 \\
\hline 4 & $\begin{array}{l}13 \\
\mathrm{PM} \\
\end{array}$ & 821.8579 & 0.0063 & 29.8 & 34.9 \\
\hline
\end{tabular}

\section{Finite Element Analysis}

A numerical method has an important contribution to solving complex computational mechanics problems, quickly and correctly. There are many methods generally used to solve a variety of problems. Each method has their own advantages and limitations. Finite element method is one which used differential equations to solve most of the problems related to automobile, civil, aerospace industries.

The CFD simulations are performed by the CFD package in the ANSYS-14.5. To gain simulated results using CFD software, a simulation procedure needs to be followed. The procedure requires setting the volume and boundary conditions of the simulated module.

A sketch of the geometry which was investigated is depicted in figure 4.1. It shows a standard flat-plate solar thermal collector where four different zones are identified: (1) the sheet-and-tube assembly, which consists of six $11.58 \mathrm{~mm}$ ID tubes, separated $115 \mathrm{~mm}$ and welded to a copper absorber plate along their upper generatrix. (2) A glass sheet which is transparent, which covers the absorber plate and reduces the convection and radiation losses to the ambient. (3) The air filled cavity between the glass and the absorber plate at atmospheric pressure. (4) An insulating layer of rockwool that covers the lateral and bottom sides of the assembly to minimize the conduction and convection losses to the surroundings.

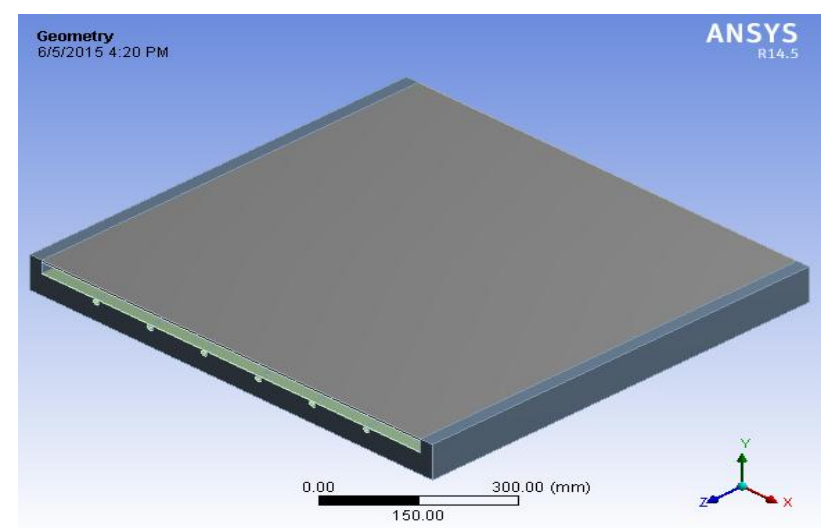

Fig.4 Geometry of solar flat plate collector model

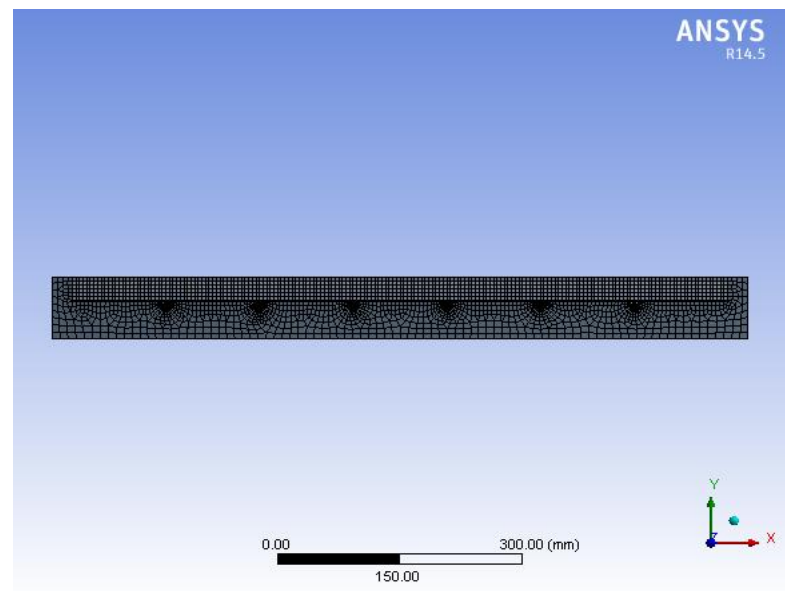

Fig.5 Meshing 


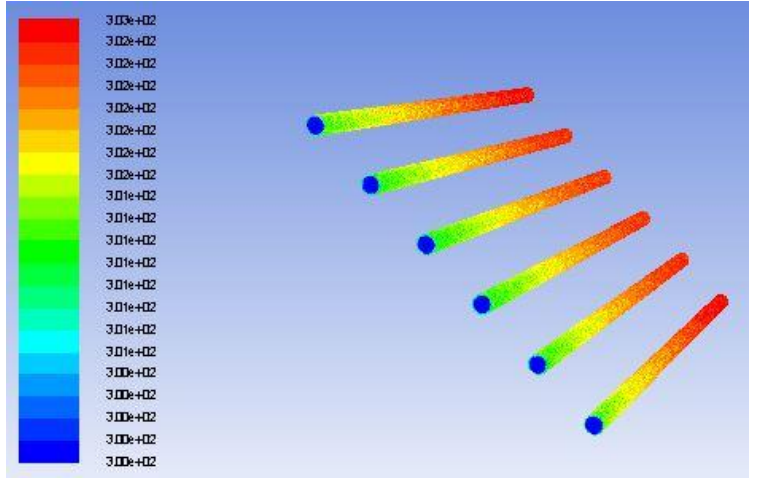

Fig.6 Temperature Contour at $10 \mathrm{AM}$

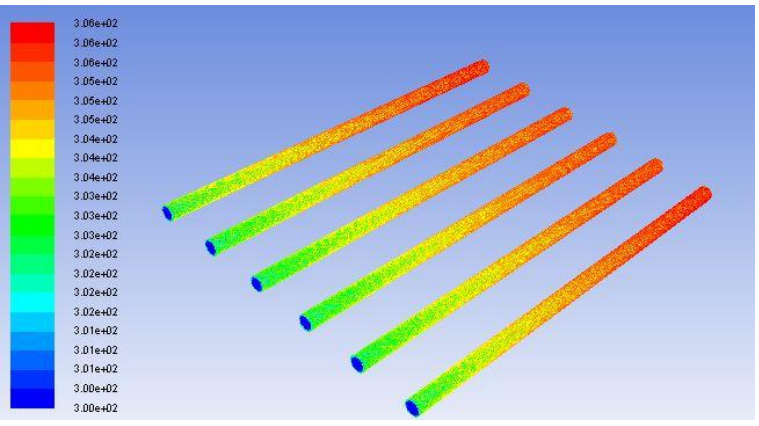

Fig.7 Temperature Contour at 12 PM

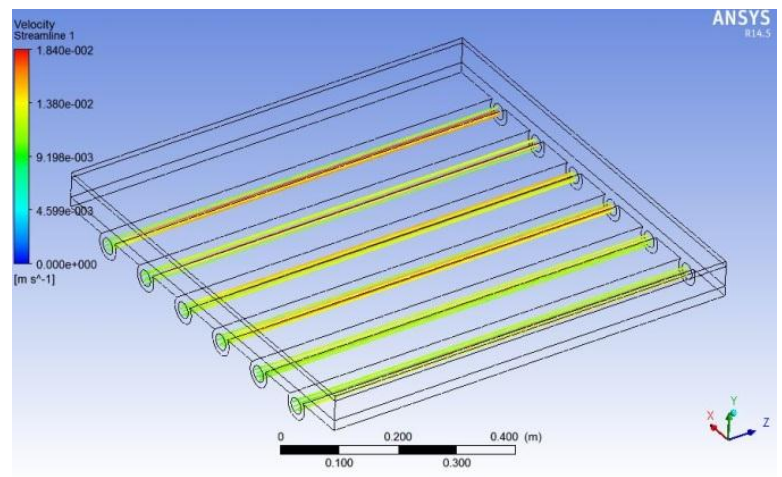

Fig.8 Streamline flkow in pipe

The maximum velocity recorded at pressure outlet was found to be $1.87 \mathrm{~m} / \mathrm{sec}$, velocity at outlet reduces from the inlet velocity of $2 \mathrm{~m} / \mathrm{sec}$ due to frictional losses and turbulence. The streamline can be seen in the above figure in order to know the profile of flow of water through pipes from velocity inlet to outlet

\section{Result and Discussion}

In order to verify the accuracy of the calculation results, the simulation values are compared with the values obtained from Experimental observation.Outlet fluid temperature is a measure of net heat gain from incident solar heat flux. By absorbing the incident solar heat flux on particular day at different timings, the outlet fluid temperature is varying. Thus below figure shows variation of outlet temperature of SFPC experimentally and numerically.

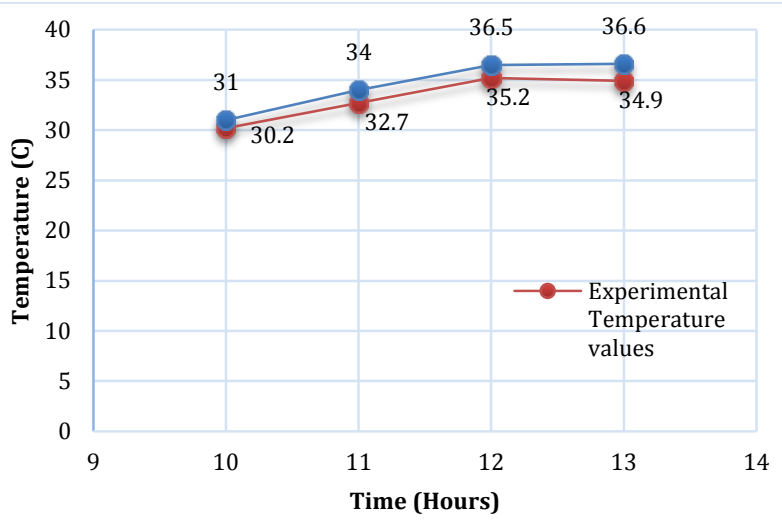

Fig.9 Experimental versus Simulation Results

\section{Use of V corrugation over absorber plate}

In order to compare normal solar flat plate collector with $\mathrm{V}$ corrugated absorber plate collector a model of new Solar flat plate collector has been generated with $\mathrm{v}$ corrugations over absorber plate. The below figure shows the model of SFPC designed with $\mathrm{V}$ corrugation over absorber plate.

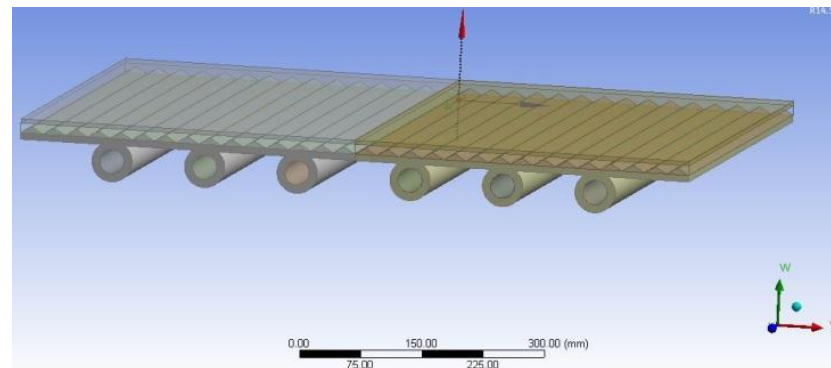

Fig.10 Solar FPC with V corrugated absorber plate

In order to avoid high number of nodes and meshed elements, for saving computation time insulation has not been considered. The insulation wall boundary condition has been provided below the pipes. Based on the results obtained of outlet temperature it was found that SFPC with V corrugation over absorber plate are more efficient than normal FPC. The comparison of outlet temperature is shown below.

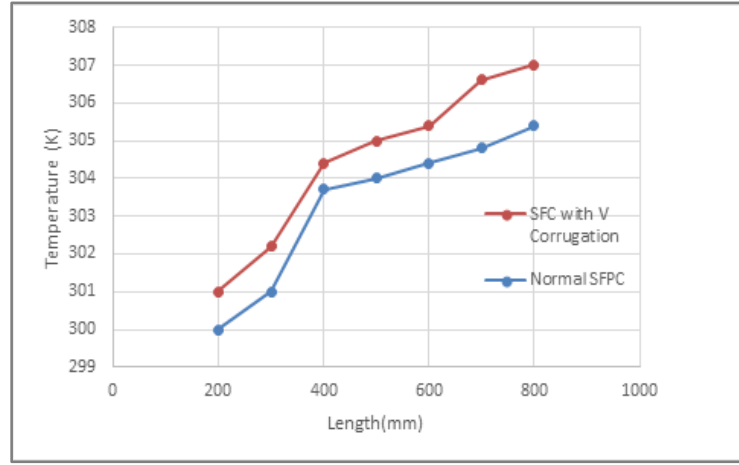

Fig.11 Normal SFPC versus SFPC with Fins 


\section{Effect of Air Gap thickness}

When the size of the air gap was very small, the heat transfer from glass to absorber plate is dominated by conduction. As the gap between the glass and absorber plate is increased, natural convection takes place which leads to an increase in the convective heat loss.

From the figure 5.8 the top loss coefficient is increased with the air gap up to some extent but after certain limit of gap net heat gain in terms of outlet fluid temperature will decrease because when thickness of gap will increase, shadow of side wall will be created on the absorber plate so net heat flux will be concentrated on certain area of absorber plate.

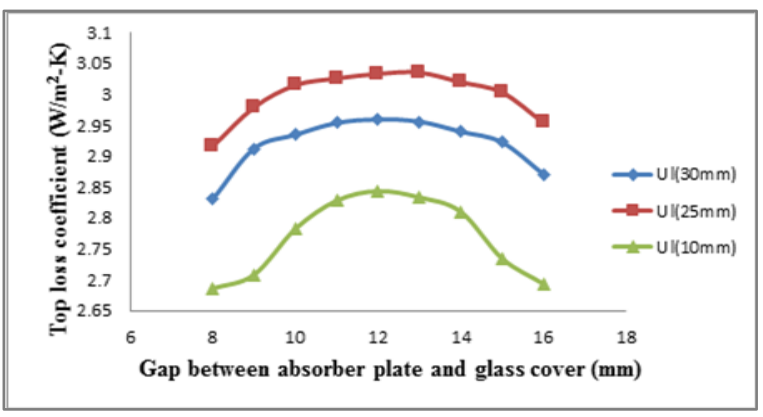

Fig.12 : Effects of gap between absorber plate and cover

Effect of different gases used between absorber plate and glass cover:

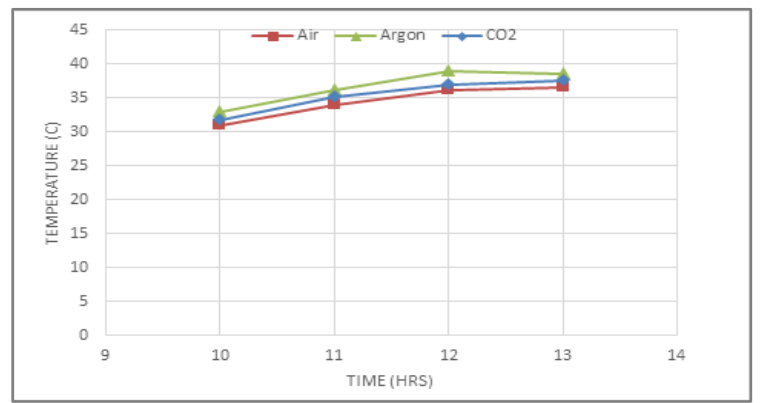

Fig.13 Overall loss coefficients using different fluids

Figure 13 shows the effect of different gases between the gap of absorber plate and glass cover. Here, air, carbon dioxide and inert gas like argon have been used. We can observe that in case of air overall heat loss coefficient is more for carbon dioxide and air and argon gas has the lowest heat losses. Argon (inert gas) has more absorption capacity related to temperature at different wavelength that reduces the heat loss.

\section{Use of Double Glazing}

As we can observe from figure below in case of double glazing i.e. two glass cover outlet fluid temperature is more than single glazing. In case of double glazing air gap is $20 \mathrm{~mm}$ provided between top glass cover and second glass cover. In this case more heat is trapped inside the glass cover that will reduce the heat losses hence outlet fluid gets more heated

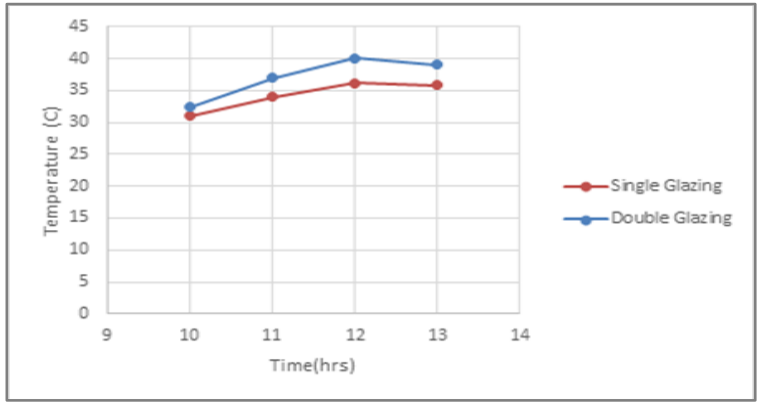

Fig.14 Comparison of Double and Single Glazing

By using double glazing more radiation is trapped and re-radiation losses would be minimized, hence the overall loss coefficient is more in case of single glazing is more compared to the double glazing

\section{Conclusion}

From the given study it is observed that The maximum difference between numerical and experimental results is less than $4 \%$.

Based on comparative study of normal SFPC and SFPC with $\mathrm{V}$ corrugated absorber plate, it was observed that SFPC with V corrugation has much more heat transfer due to increased turbulence(enhancing heat transfer through convection) and reflectance(enhancing heat transfer through radiation reflection and absorption).

The size of the gap between the absorber plate and glass cover is investigated and it is found that there is certain limit for gap and it is good to have small air gap. When different gases like air, carbon dioxide and argon have been used. We observed that in case of air overall heat loss coefficient is more for carbon dioxide and while carbon dioxide has more heat loss coefficient then argon and argon gas has the lowest heat losses. Argon (inert gas) has more absorption capacity related to temperature at different wavelength that reduces the heat loss.

\section{References}

Duffie J. and Beckmann W., Solar engineering of thermal processes, 2nd edition Wiley Interscience, New York 1991.

Klein S., Duffie J., and Beckman W., Transient considerations of flat-plate solar collectors, Trans. of ASME: Journal Engineering for Power vol. 1974 96A, pp. 109-113.

Wang X. and Wu L., Analysis and performance of flat-plate solar collector arrays, solar energy, 45, 1974, 2, 71-78.

Oliva A., Costa M., and Perez Segarra C., Numerical simulation of solar collectors: the effect of non uniform and unsteady state of boundary conditions, Solar Energy, 1991, 47, 5, 359-373.

Anderson T., Duke M., and Carson J., The effect of color on the thermal performance of building integrated solar collectors, Solar Energy Materials \& solar cells, 2010, 350-354.

K.P. Gertzos, Y.G. Caouris, Experimental and computational study of the developed flow field in a flat plate integrated collector storage (ICS) solar device with recirculation, experimental Thermal and Fluid Science 31(8) 2007, 1133-1145.

Cadafalch J., A detailed numerical model for flat-plate solar thermal devices, Solar Energy Vol. 83, 2009, pp. 2157-2164.

Martinopoulos G., CFD modeling of a polymer solar collector, Renewable Energy Vol. 35, 2010, pp. 1499-1508.

Kumar, A. and Kim, M.H., Convective heat transfer enhancement in solar air channels. Applied Thermal Engineering, 89, pp.239-261.2015

Rangababu, J.A., Kumar, K. and Rao, S., 2015. Numerical Analysis and Validation of Heat Transfer Mechanism of Flat Plate Collectors. Procedia Engineering, 127, pp.63-70. 